\title{
A ASSISTÊNCIA ELEITORAL DAS NAÇÕES UNIDAS NO HAITI: PROMOÇÃO DA DEMOCRACIA E PATOLOGIAS INSTITUCIONAIS NO PROCESSO DE ESTABILIZAÇÃO DA PAZ ${ }^{1}$
}

Wemblley Lucena de Araújo ${ }^{2}$

\begin{abstract}
Resumo
O presente trabalho objetiva analisar o papel da assistência eleitoral promovido pela Organização das Nações Unidas (ONU) nos processos de estabilização de cenários pós-conflitos, trazendo a experiência do Haiti para o debate, e a partir desta, diagnosticar os principais avanços e dificuldades enfrentadas pela atuação onusiana no campo da assistência eleitoral. Para tanto, o presente estudo utilizar-se-á dos métodos analíticos, qualitativos e bibliográficos atuando em fontes primárias (resoluções e informes oficiais) e secundárias (literatura especializada). Conclui-se que a atuação onusiana no Haiti no campo da assistência eleitoral contribuiu para a minimização dos entraves políticos, realização das eleições periódicas e democráticas, porém patologias institucionais retardaram o andamento dos processos pré-estabelecidos levando-os a, em certa medida, incongruências em face da realidade haitiana.
\end{abstract}

Palavras-chave: Nações Unidas. Assistência Eleitoral. Eleições. Haiti.

\begin{abstract}
The present work aims analyze to the role of electoral assistance promoted by the United Nations (UN) in the processes of stabilization of post-conflict scenarios, bringing the Haiti experience to the debate, and from this, diagnose major advances and difficulties faced by onusiana performance in the field of electoral assistance. Therefore, this study will be used analytical, qualitative and bibliographic methods acting on primary sources (resolutions and papers) and secondary (specialized literature). It follows that the onusiana operations in Haiti in the field of electoral assistance helped to minimize the political barriers, and purpose of the periodic democratic elections, but institutional conditions slowed the progress of pre-established processes leading them to a certain extent, inconsistencies in the face of the Haitian reality.
\end{abstract}

Keywords: United Nations. Electoral Assistance. Elections. Haiti.

\section{Resumen}

Este trabajo tiene como objetivo analizar el papel de la asistencia electoral promovido por las Naciones Unidas (ONU) en los procesos de estabilización de escenarios post-conflicto, con lo que la experiencia de Haití para el debate, y de esto, el diagnóstico de los principales avances y dificultades que enfrentan por onusiana desempeño en el campo de la asistencia electoral. Por lo tanto, este estudio se utilizará métodos analíticos, cualitativos y bibliográficas que actúan sobre las fuentes primarias (resoluciones y documentos) y secundaria (literatura). De ello se desprende que las operaciones onusiana en Haití en el campo de la asistencia electoral ayudaron a minimizar las barreras políticas, y el propósito de las elecciones democráticas periódicas, pero las condiciones institucionales frenaron el avance de los procesos preestablecidos que conducen a un cierto punto, inconsistencias en la cara de la realidad de Haití.

Palabras clave: Naciones Unidas. Asistencia Electoral. Elecciones. Haití.

\footnotetext{
${ }^{1}$ DOI deste artigo: $10.5380 /$ recp.v6i1.39228.

${ }^{2}$ Mestre em Relações Internacionais pelo Programa de Pós-Graduação em Relações Internacionais (PPGRI) da Universidade Estadual da Paraíba (UEPB). Bacharel em Relações Internacionais na mesma instituição. Email: wemblley@gmail.com
} 


\section{INTRODUÇÃO}

Diante das complexidades advindas das sociedades pós-conflitos no pós-Guerra Fria, ao considerar atuação da Organização das Nações Unidas (ONU) no campo da assistência eleitoral, deve-se elencar alguns pontos de entendimentos. Primeiro, calcando-se na perspectiva da Paz Democrática (Doyle, 2010; Owen, 1999), oriunda da concepção kantiana do projeto de paz no plano internacional (KANT, 2008), a ONU utiliza o modelo de Estado democrático, pois percebe neste, o modelo preferencial para a manutenção da ordem doméstica e, consequentemente, a estabilidade do sistema internacional. De fato, este modelo evidencia características básicas como o compromisso político, responsabilidade de resposta perante aos cidadãos, garantia da liberdade de expressão e respeito aos direitos humanos. Muitas dessas características contribuem para melhores relações políticas, estabelecimento de entendimento mútuo, resolução de controvérsias por meios pacíficos, além de dá previsibilidade comportamental dos principais atores antagônicos, reduzindo assim, eventuais constrangimentos políticos potencialmente existentes.

O campo da assistência eleitoral se configura como uma estratégia de reconstrução da paz ligada à promoção do papel dos princípios democráticos na reconstrução da capacidade política institucional de Estados conturbados por conflitos. Desta forma, a ONU desenvolve políticas direcionadas à reconstrução de Estados conturbados, no entanto, as atividades de tais operações sofreram significativas transformações ao longo das décadas de atuação, a própria redefinição da concepção de paz, levou a ONU a se inserir em contextos para a promoção de uma paz positiva (GALTUNG, 1969), ou seja, direcionadas para as atividades de peacebuilding.

Nesse sentido, a atuação da ONU no Estado haitiano se traduz em um estudo de caso emblemático, pese a raiz do conflito, eminentemente devido às transições políticas traumáticas e constantes disputas pelo poder, o campo da assistência eleitoral tem, além de vincular-se a promoção dos princípios democráticos promove a estabilização política no Estado haitiano. Para melhor compreensão e sistematização do tema em discussão, o trabalho está estruturado em nas seguintes seções, a saber: primeiramente, abordar-se-á sobre a instabilidade histórica haitiana e a chegada da ONU no Haiti; em seguida, discutir-se-á sobre a institucionalização da assistência eleitoral no âmbito das Nações Unidas; e, por fim, analisar-se-á a atuação onusiana, através da Missão de Estabilização das Nações Unidas no Haiti (MINUSTAH) no campo da assistência eleitoral ao longo dos governos haitianos (Governo de Transição, René Preval e Michel Martelly). 


\section{DA DISPONIBILIDADE HAITIANA A CHEGADA DA INTERVENÇÃO ONUSIANA: CONTEXTUALIZAÇÃO HISTÓRICA}

A instabilidade haitiana é histórica, deste o seu processo de independência aos recentes governantes atuais, o Estado caribenho tem sofrido diversas lutas pelo poder e transições traumáticas. O processo de independência haitiano teve seu início por volta de 1789, com base nos ideais da Revolução Francesa que aos poucos vinham chegando à Ilha de Hispaníola ${ }^{3}$. Absorvendo esses princípios, essa região enfrentou uma rebelião provocada pelos escravos, liderada pelo ex-escravo Toussaint L'Ouverture, esse movimento desencadeou em significativas transformações na colônia francesa. Nesse contexto, em janeiro de 1804, Jean-Jacques Dessalines proclamou o Haiti um Estado independente, tornando-o a primeira república negra independente e a segunda república independente das Américas (CAVALLARO, 2005, p. 4).

Dois anos depois da independência haitiana, Dessalines foi executado pela oposição doméstica, e, a partir daquele momento, o Haiti mergulhou numa grave crise interna sem precedentes. Entre 1807 e 1915, a conjuntura haitiana foi abalada por diversos conflitos que tinham por natureza a instabilidade política, diversas revoltas desestabilizavam os governantes do Haiti (BUSS, 2008, p. 21). Conforme Câmara:

\footnotetext{
(...) sem líderes expressivos ou confiáveis para conduzir a política nacional, recuperar a economia e instalar um sistema administrativo competente, a antiga "Pérola das Antilhas" dos franceses, assim chamada no período colonial por sua prosperidade econômica, mergulhou numa espiral de violência e anarquia política que só seria interrompida em 1915, com a intervenção militar dos Estados Unidos (CÂMARA, 1998, p. 51).
}

Em 1915, quando o presidente haitiano Guillaume Sam foi brutamente assassinado, uma onda de violências se instalou no Haiti. Diante daquela situação e considerando a possibilidade de uma intervenção da Alemanha no Haiti durante a Primeira Guerra Mundial, os EUA iniciaram uma ocupação no Haiti que durou de 1915 a 1934, além disso, vale ressaltar que o presidente estadunidense Woodrow Wilson tinha como um dos objetivos de sua política externa promover um projeto de democratização de alcance global. No entanto, os EUA deixaram o Haiti em 1934, sem prepará-lo, sem ter desenvolvido nenhum mecanismo que viabilizasse a reorganização da política haitiana (BUSS, 2008, p. 23).

As transições de poder no Haiti sempre foram caracterizadas por violentos conflitos, observa-se que entre os anos de 1956 e 1957 o Haiti teve quatro governantes no poder

\footnotetext{
${ }^{3}$ A Ilha de Hispaníola corresponde ao atual território do Haiti e da República Dominicana.
} 
(BUSS, 2008, p. 24). Desta forma, as diversas sucessões de poder sempre traumáticas e conflituosas levavam a aquele que assumisse, a resistir até as últimas consequências a fim de se manter no controle do poder nacional.

Em 1957, diante da instabilidade política no Haiti e considerando as implicações no campo da segurança regional, os EUA financiaram a campanha de Francis Duvalier (o Papa Doc) que logo após diversas rodadas de eleições mal sucedidas, assumiu o poder de forma arbitrária e, imediatamente, instaurou uma feroz ditadura que foi caracterizada pelo medo e na opressão de seus opositores. De acordo com Cavallaro (2005, p. 5), "Duvalier substituiu as forças armadas por agentes de segurança particular, os Tontons Macoutes ${ }^{4}$, que viraram o símbolo duradouro da ditadura".

Diante da morte de Papa Doc em 1971, o povo haitiano experimentou um relativo momento de esperança, ou seja, acreditava-se que o novo governante poderia reestabelecer a política local, no entanto, através de uma ementa constitucional, o poder foi repassado ao seu filho, Jean-Claude Duvalier (Baby Doc). No início do governo de Baby Doc, com as praticas de liberalização política, ocorreu um considerável desenvolvimento econômico no Haiti, possibilitando em certa medida, o início da estruturação de uma sociedade civil organizada. No entanto, os ganhos advindos do incipiente desenvolvimento passaram a ser violados pelos políticos locais, configurando assim, em recorrentes práticas de corrupção na política haitiana, além disso, o nível de autoritarismo passou ser uma das características dominantes do Estado haitiano (FATTON, 2006. p. 18). Câmara (1998, p. 50), ao analisar a história da política do Haiti, afirma que a ausência de comprometimento das lideranças políticas com a democratização das instituições nacionais foi elemento decisivo para desestabilização do Estado haitiano.

Em 1990, recebendo a maioria dos votos, Jean-Bertrand Aristide foi eleito presidente do Haiti e para conseguir esse feito, Aristide contou com apoio popular, principalmente da população mais pobre, que cansada dos regimes duvalieristas, do autoritarismo e da repressão dos militares, viam no novo presidente a esperança de uma possível reestruturação da ordem e da política doméstica. Nesse contexto de instabilidades, a chegada da intervenção das operações de paz onusianos no Haiti vem tentar minimizar os conflitos domésticos e promover princípios democráticos no Estado Haitiano. Patriota (2010, p. 120) ressalta que

\footnotetext{
${ }^{4}$ Os Tontons Macoutes eram uma espécie de um grupo paramilitar que se caracterizavam por ações hostis, promovendo o medo e a opressão contra aos grupos políticos e indivíduos que se posicionavam como opositor as ações do Pap Doc.
} 
“a OEA ${ }^{5}$ e a ONU haviam colaborado em 1990 na observação das eleições haitianas que deram vitória a Jean Bertrand Aristide pela maioria expressiva de 67\% do eleitorado".

Deste modo, inconformados com os resultados da eleição, os militares organizaram um golpe para inviabilizar a chegada de Aristide ao poder, mas inicialmente falharam. Assim, Aristide assumiu o poder em fevereiro de 1991, tendo René Préval na qualidade de primeiro ministro (BUSS, 2008, p. 30). Nos primeiros meses de seu governo, Aristide tentou se consolidar no comando do Haiti, no entanto, adotando um forte posicionamento político, começou a fechar associações políticas domésticas, impedindo a manifestação da oposição, além disso, muitos dos que tinham o ajudado a se eleger não foram nomeados na sua administração, fato que causou um enorme ressentimento político, Aristide rompeu com oficiais, juízes e com a polícia que a ele próprio tinham o apoiado (BUSS, 2008, p. 30).

Em 30 de setembro de 1991, meses depois de tomar posse, Aristide sofreu um golpe militar arquitetado pelo comandante das Forças Armadas do Haiti (Roaul Cédras) e apoiado pela elite econômica, fato que levou o presidente Aristide para o exílio nos EUA (INTERNATIONAL CRISIS GROUP, 2004, p. 4) ${ }^{6}$. Diante desse cenário, ondas de violências e instabilidades se sucederam no Haiti, incluindo uma saída em massa de refugiados, sanções econômicas por meio de mandatos da OEA e do CSNU, até que a ONU desenvolveu sucessivas missões na tentativa de mediação e, finalmente, não solucionada a situação, a intervenção militar multinacional liderada pelos EUA em 1994 para restaurar a democracia e reempossar o presidente Aristide ao poder (HAGMAN, 2002, p. 2).

No início de fevereiro de 2004, explodiu um conflito armado na cidade de Gonaives, pouco a pouco a revolta foi se alastrando para outras cidades até chegar a capital de Port-auPrince. Aristide não resistiu às pressões internas e acabou abandonando o Haiti nas primeiras horas do dia 29 de fevereiro de 2004 imediatamente, o então Primeiro Ministro Yvon Neptune leu sua carta de demissão, e em seguida, Boniface Alexandre, Presidente da Suprema Corte, assumiu o cargo de presidente interino, em conformidade com as normas constitucionais sobre sucessão. Logo depois, o representante permanente do Haiti diante das Nações Unidas, apresentou a solicitação de assistência ao governo interino, na qual autorizava a entrada de tropas internacionais no Haiti, atendendo a essa solicitação o

\footnotetext{
5 Organização dos Estados Americanos.

${ }^{6} \mathrm{Em}$ face da instabilidade política que se desencadeou no Haiti, os três anos de governo apoiado pelos militares que se seguiram foi caracterizado pelo retorno de repressão patrocinada pelo Estado, com "esquadrões da morte" de direita visando partidários de Aristide em grupos de camponeses, o comércio sindicatos e organizações de base, nessa conjuntura cerca de 3.000 a 5.000 pessoas foram assassinadas (INTERNACIONAL CRISIS GROUP, 2004, p. 4).
} 
Conselho de Segurança através da resolução 1529 (2004), autorizou a Força Multinacional Provisória (FMP) ${ }^{7}$ a iniciar o seu mandato de acordo com a resolução estabelecida ${ }^{8}$.

Diante da necessidade de formalizar uma operação mais consistente de caráter multidimensional, que melhor atendesse a necessidade haitiana, o Conselho de Segurança da ONU, através da resolução 1542 de 30 de abril de 2004, estabeleceu a MINUSTAH, por um período inicial de seis meses, com a intenção de prorroga-la por novos períodos, pedindo assim, que a autoridade da FMP fosse transpassada a MINUSTAH em $1^{\circ}$ de junho de $2004^{9}$.

Indubitavelmente, em face de crises cíclicas e contextos específicos conturbados, a dimensão política se configura como o eixo da instabilidade haitiana. De fato, as crises políticas no Haiti e sua desestabilização político-institucional levaram às operações de paz onusianas que tinham como propósito garantir a ordem doméstica e permitir o desenvolvimento de um ambiente político estável no Estado haitiano. Nesse contexto, o campo da assistência eleitoral, função diretamente ligada ao aspecto político, raiz dos conflitos no Haiti, se configura como uma esfera essencial para minimizar as divergências entre grupos antagônicos e promover a paz e a segurança através da construção e fortalecimento de instituições político-democráticas.

\section{INSTITUCIONALIZAÇÃO DA ASSEMBLEIA ELEITORAL DAS NAÇÕES UNIDAS}

O campo da assistência eleitoral promovido pela ONU nasceu em função do dispositivo de autodeterminação dos povos consagrado na carta de São Francisco de 1945. Historicamente, inclui o princípio de autodeterminação dos povos, principalmente no período de descolonização, utilizando-se de relativas atuações na promoção da autonomia e no desenvolvimento dos novos atores internacionais. Em um período mais recente da nossa história, esta dimensão se insere em contextos com a finalidade de contemplar o estabelecimento e o avanço dos princípios democráticos, além de assegurar a garantia dos Direitos Civis e Políticos. Desta forma, o campo da assistência eleitoral deve ser entendido com base numa concepção holística consoante com a especificidade da situação.

\footnotetext{
7 A Força Multinacional Provisória - (FMP) foi autorizada pelo Conselho de Segurança de acordo com a Resolução S/RES/1529 de 29 de fevereiro de 2004, com o objetivo de "[...] apoiar a continuação de um processo pacífico e constitucional, mantendo um ambiente seguro e estável no Haiti [...], [tradução livre]” (UN. doc. S/RES/1529, 2004, p. 2, \ 3).

${ }^{8}$ UNITED NATIONS. doc. S/2004/300, 2004, p.3, \ 9.

${ }^{9}$ UNITED NATIONS. doc. S/2004/698, 2004, p.1, § 1.
} 
No plano internacional, as eleições ficaram claramente explícitas na Declaração Universal de Direitos Humanos (1948), e logo depois com a Declaração de Direitos Civis e Políticos (1966). No entanto, a conjuntura da época não favorecia a efetivação desses princípios, segundo Melo (2006, p. 269-270), mesmo com um expresso desenvolvimento normativo do regime internacional de direitos humanos, o início da Guerra Fria impediu que a ONU desenvolvesse um papel significativo na democratização de Estados, durante esse período tanto o regime internacional de direitos humanos como as normas de democracia tinham pouco alcance prático, apenas no final da Guerra Fria, a partir de 1988, quando o projeto socialista-ideológico agonizava e a concepção de democracia liberal ganhava força, é que a Assembleia Geral das Nações Unidas (AGNU) passou a considerar com mais ênfase as questões ligadas ao fortalecimento do princípio de eleições livres e justas dentro dos Estados. No pós-Guerra Fria, com o fim da paralisação do Conselho de Segurança das Nações Unidas (CSNU) provocado pela bipolaridade político-ideológico, a ONU passou a ser mais atuante e incisiva na promoção dos valores democráticos calcados em eleições livres e críveis, assim, introduziu esses princípios como normativos e os institucionalizou em seus subórgãos institucionais.

Em dezembro de 1991, a AGNU deu seu primeiro passo para a institucionalização das atividades de assistência eleitoral adotada através da Resolução S/RES/46/137 proposta pelos Estados Unidos (LUDWIG apud MELO, 2006, p. 270). A resolução designou ao Secretário Geral Adjunto para Assuntos Políticos (Departamento de Assuntos Políticos DPA) delegando a este, a função de coordenar as atividades de assistência eleitoral, para centralizar o foco dessa dimensão, criou-se a Divisão de Assistência Eleitoral (EAD), inserida dentro do DPA para auxiliá-lo a cumprir sua missão. A EAD desempenha papel fundamental na avaliação no que se refere aos pedidos de assistência eleitoral que são encaminhados as Nações Unidas, os quais passam todos pelo seu crivo.

Do ponto de vista prático, o campo da assistência eleitoral da ONU se insere em dois principais objetivos: (i) assistir os Estados membros em seus esforços na realização de eleições democráticas legítimas, de acordo com os critérios internacionais definidos pelos mecanismos universais e regionais de direitos humanos; (ii) contribuir na construção da capacidade institucional dos países para organizar eleições democráticas que sejam genuínas e periódicas, e que conte com a confiança total de todos os partidos disputantes e do eleitorado (ELECTORAL ASSISTENCE IMPLEMENTATION GUIDE, 2007).

O papel da assistência eleitoral em Estados pós-conflitos é basicamente assegurar a realização dos processos eleitorais, através de atividades sistematicamente planejadas, a fim 
de garantir a legitimidade e a imparcialidade desses processos eleitorais, promovendo a substituição de uma competição violenta pelo poder político por transições pacíficas calcadas em valores democráticos amplamente aceitáveis pela população, além de fortalecer a capacidade institucional do Estado receptor. O campo da assistência eleitoral, que inicialmente apenas visava à garantia da realização de eleições livres e justas nos processos eleitorais, vem ampliando sua concepção, principalmente diante das novas necessidades de controle estatal e governança, esse setor passa a se inserir em todas as fases do processo de democratização de Estados.

\section{FUNÇÕES OPERACIONAIS E PLANEJAMENTO ELEITORAL}

De acordo com o Handbook on UN Multidimensional Peacekeeping Operations (2003), no âmbito das operações de paz, são identificadas cinco funções operacionais para o campo da assistência eleitoral.

- Supervisão Eleitoral: Sob um mandato de supervisão eleitoral, o Secretário Geral da ONU deve além de identificar e certificar os resultados, também participar de todas as fases do processo eleitoral.

- Verificação Eleitoral: Essa se insere quando o país realiza as suas próprias eleições, mas pede ajuda das Nações Unidas, para verificar os aspectos de liberdade e justiça nos mecanismos dos processos eleitorais.

- Organização e Condução das Eleições: Neste caso, a ONU é chamada a executar uma eleição, cumprindo a função e a responsabilidade de uma administração nacional eleitoral. $\mathrm{Na}$ organização das eleições a ONU deve recrutar, treinar, implantar e pagar todos os agentes eleitorais envolvidos no processo.

- Assistência Técnica Eleitoral: Esse é o tipo de assistência eleitoral mais praticado pela ONU, com base nos requisitos do país em questão, as atividades podem incluir fornecimento de análises, conselhos, treinamentos e equipamentos para instituições governamentais, além disso, a assistência técnica pode estar inserida em qualquer área da administração eleitoral.

- Coordenação e Suporte aos Observadores Internacionais: Esta é uma função utilizada quando vários países, organizações internacionais e ou ONG’s foram convidados pelo Estado receptor para observar suas eleições. O objetivo reside em integrar e coordenar esses atores internacionais em seus esforços de observação. 
Embora o planejamento eleitoral possa ser realizado no âmbito de uma operação de paz, nada garante que ele seja executado como planejado, isso se deve muito as disposições dos recursos (materiais, pessoal, militar e econômico) das capacidades da operação, além disso, o contexto interno exerce papel decisivo na execução das atividades em campo e o planejamento inicial estabelecido pode ser modificado e alterado inúmeras vezes.

O planejamento eleitoral tem início com uma força tarefa multidisciplinar (IMTF) que é estabelecida no âmbito da ONU e passa a desenvolver preparativos para anexação do setor eleitoral em uma missão de paz. A EAD (Divisão de Assistência Eleitoral) representa o ponto focal onde se estabelecem um fórum para identificar e assegurar as questões eleitorais que venham a ser desenvolvidas. Entre as discussões alguns fatores são cruciais nessa fase decidir o sistema eleitoral a ser adotado, os critérios para o direito a voto, estabelecendo assim, o nível de envolvimento apropriado da ONU através das funções operacionais e as atividades que podem ser viáveis em um determinado período (HANDBOOK ON UN MULTIDIMENSIONAL PEACEKEEPING OPERATION, 2003)

Num segundo momento, o planejamento eleitoral passa para a fase de um planejamento de um acordo de paz, onde um Representante Especial do Secretário-Geral negocia o nível de envolvimento e recomenda ao Secretário-Geral um direcionamento de ação que é apresentado ao CSNU, levando em consideração o que foi discutido e apurado anteriormente na IMTF. Posteriormente, uma missão eleitoral de reconhecimento, NAM (Needs Assement Mission) é liberada pela EAD para conduzir uma ampla análise da situação local no campo eleitoral, objetivando analisar as capacidades nacionais e prospectos para a realização das eleições. O relatório final que contém avaliação realizada pela NAM deve conter questões substanciais sobre o planejamento e composição do componente eleitoral. No caso de um mandato aprovado pelo CSNU para uma operação de paz contendo um extensivo envolvimento do setor da assistência eleitoral, a NAN pode recomendar o despacho de um grupo de planejamento avançado para fornecer um plano amplo e detalhado da missão eleitoral (MELO, 2006, p. 228).

Diante das complexidades advindas dos contextos internos em Estados pós-conflitos e tentando nortear as atividades da assistência eleitoral da ONU, o United Nations Development Programme (UNDP) lançou em 2007, o Electoral asssitance implementation guide, este fornece tanto as operações de paz como também ao DPA/EAD sugestões, através de experiências acumuladas no campo da assistência eleitoral, para à implementação e o desenvolvimento de estratégias das atividades ligadas ao setor eleitoral. A inovação que o guia traz reside no 
estabelecimento de um ciclo eleitoral para nortear a condução desse setor em campo. O ciclo eleitoral leva em consideração as diferentes fases do processo eleitoral e institucional, ampliando assim o espectro da assistência eleitoral como se pode visualizar na figura a seguir.

Figura 1 - Ciclo Eleitoral

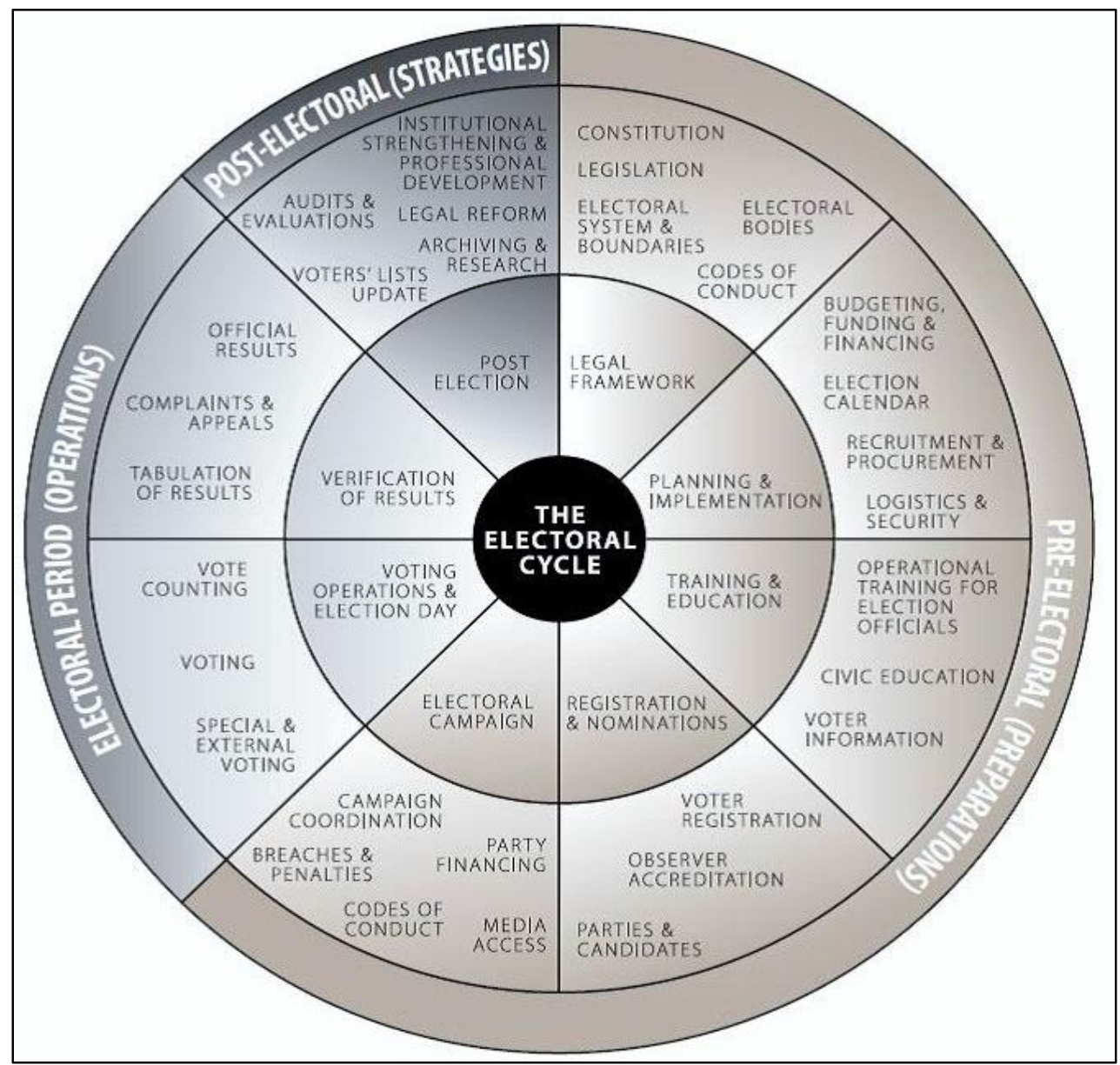

Fonte: Electoral assistance implementation guide, 2007.

O ciclo eleitoral é característico da necessidade de planejamento em função da periodicidade na realização dos processos eleitorais em Estados pós-conflitos. Diante da figura supraexposta identifica-se a presença de três momentos estratégicos para o desenvolvimento dessas atividades no campo da assistência eleitoral, são eles a seguir:

- Perído Pré-Eleitoral: nesse período também conhecido como preparatório, há a observância da estruturação legal ou reforma legal, como ajustes na lei eleitoral, os limites dos órgãos eleitorais, códigos de conduta nas eleições; implementação das atividades, com o estabelecimento do orçamento, financiamento, recrutamento e aquisição dos recursos, elaboração do calendário eleitoral, promoção do treinamento e orientação quanto a informações sobre o voto; registro e nomeação, com a validação 
dos observadores, partidos políticos e candidatos; e campanha eleitoral, com o estabelecimento do que se consideram violações e penalidades, os meios de acesso à propaganda e a mídia, e a fiscalização do financiamento dos partidos políticos.

- Período Eleitoral: período conhecido como operacional, corresponde à operacionalização do voto, execução do voto externo especial, controle do processo de votação e a verificação dos resultados, com o processo de contagem dos votos, análise das reclamações, tabulação e estabelecimento do resultado oficial.

- Periodo Pós-Eleitoral: período destinado ao fortalecimento das estratégias, realização de auditorias e avaliações, atualização das listas de eleitores, arquivamento e pesquisa, retorno à reforma legal, desenvolvimento profissional e fortalecimento institucional.

O ciclo eleitoral infere-se, na complexidade, na medida em que fornece um ponto de referência para o andamento dos processos eleitorais, assim, adota-se o sentido de uma percepção holística e sustentável das eleições, com processos cíclicos em andamento, de natureza dinâmica, que estão incorporados em contextos mais amplos da governança democrática.

Cumpre considerar que o ciclo eleitoral apresentado foi estabelecido para guiar, orientar, nortear o planejamento das atividades de assistência eleitoral, e que, não necessariamente, pode ou deve ser seguido analiticamente na prática, ou seja, o planejamento eleitoral não é absoluto, além disso, as variáveis domésticas estão constantemente gerando necessidades não previstas e muitas vezes, possíveis mudanças no planejamento inicialmente estabelecido são necessárias, para que o andamento do campo da assistência eleitoral esteja adequado às necessidades local.

Um caso emblemático da atuação onusiana no campo da Assistência eleitoral se dá no Haiti. Desta forma, antes de adentrarmos a uma análise desta experiência, a priori, passarse-á a compreender como se deu a necessidade de auxilio da ONU no Haiti e seu papel no processo de estabilização da paz.

\section{A ASSistênCIA ElEITORAL DA ONU NO HAITI: PROMOÇÃO DA DEMOCRACIA E PATOLOGIAS INSTITUCIONAIS}

A seguir analisar-se-á o desempenho da ONU no campo da assistência eleitoral com base no recorte temporal 2004-2014, assim compreenderemos sobre as estratégias traçadas, atividades executadas, avanços e dificuldades para o exercício do pessoal da MINUSTAH em campo e seus efeitos diante das complexidades advindas do contexto local haitiano. Para 
isso, passaremos por três períodos, o Governo de Transição (2004-2006), o Governo René Préval (2006-2011) e o Governo de Michel Martelly (2011-2014).

\subsection{Governo de Transição (2004-2006)}

O governo de transição se formou logo após o abandono do então Presidente Aristide no dia 29 de fevereiro de 2004, assumindo assim, o então Primeiro Ministro Yvon Neptune que leu a carta de demissão deixada pelo Presidente Aristide, e em seguida, assumiu o Boniface Alexandre como Presidente interino. No entanto, devido à desestruturação interna, ficou evidente que o Haiti não conseguiria organizar suas eleições conforme o prazo prescrito, pois o contexto institucional doméstico se encontrava numa situação totalmente fragilizada e não dispunha de mecanismos que garantissem sua reorganização políticoinstitucional.

O governo de transição solicitou à ONU que lhe prestassem assistência nas eleições haitianas. Por conseguinte, a ONU enviou uma comissão ao Haiti para avaliar as necessidades eleitorais, e definir as modalidades de assistência que a comunidade internacional e em particular as Nações Unidas prestariam. A missão de avaliação das Nações Unidas formulou recomendações entorno de uma reforma na lei eleitoral haitiana, regulamentação dos pleitos, atividades de capacitação do pessoal do CEP, a prestação de assistência técnica nas questões administrativas e financeiras, no planejamento operacional, nas inscrições dos votantes, além de promover uma ampla campanha de educação cívica. Nesse contexto, a MINUSTAH é estabelecida em $1^{\circ}$ de junho de 2004, passou a proporcionar a necessária orientação, organização, supervisão do processo eleitoral além de coordenar e observar a assistência técnica internacional na realização das eleições no Estado haitiano ${ }^{10}$.

Logo que estabelecida, a MINUSTAH prestou apoio institucional ao CEP, sendo crucial para que a operação conseguisse desenvolver suas atividades, além de estruturar uma instituição ligada a assuntos políticos num contexto politicamente fragilizado. Desta forma, o papel de uma instituição internacional como a ONU através da MINUSTAH se inseria naquele momento em garantir o mínimo de legitimidade e credibilidade nos processos decisórios direcionados a questão eleitoral. Segundo Kratochwil e Ruggie (1986, p. 344), uma das potenciais funções das instituições internacionais refere-se ao seu papel organizacional na resolução de questões substanciais, para os autores o desenvolvimento de operações de

\footnotetext{
${ }^{10}$ UN. Doc. S/2004/698, 2004, p. 07, 』 34.
} 
paz reflete um exemplo emblemático desse papel ao assumir importantes funções na arena da paz e da segurança internacional.

Nos primeiros meses do governo de transição a MINUSTAH passou a mediar um processo de diálogo entre o partido Fanmi Lavalas e o governo de transição, facilitando a comunicação mediante a utilização de good offices, para tentar chegar a um acordo entre as partes, e incorporar as opiniões dos membros dos Fanmi Lavalas no processo de transição político ${ }^{11}$. Além disso, a MINUSTAH esteve participando de debates e consultas junto ao CEP, aos demais partidos políticos e com representantes da sociedade civil para estabelecer um consenso geral sobre as eleições ${ }^{12}$.

Como resultado dessas consultas e levando em consideração as diferenças entre os membros, o CEP conseguiu estabelecer várias decisões. ${ }^{13}$ Nesse fato pontual, podemos perceber que o desempenho da operação foi satisfatório, já que foi possível estabelecer um consenso geral sobre as eleições, a importância da operação na promoção do diálogo e nas articulações entre os atores opositores, foi tão determinante para aquele momento, que só através de um consenso entre os diversos grupos antagônicos é que seria possível viabilizar o processo político e eleitoral. De acordo com Jeong (2010, p. 193) um dos mecanismos facilitadores nos processos de resolução de conflitos reside na promoção do diálogo para o autor o diálogo pode dissolver a polarização de opiniões entre os grupos opositores e criar uma estrutura de entendimento entre as partes, para que estas possam encontrar uma saída para as suas divergências.

Para que as atividades de assistência eleitoral pudessem ser projetadas nesse período de transição, seria preciso conhecer todas as sub-regiões do território haitiano, verificando as reais necessidades, vulnerabilidades e potenciais ameaças à segurança do processo eleitoral, passando assim, a ser uma preocupação para a MINUSTAH ter esse tipo de conhecimento, para isso, no dia 09 de Fevereiro de 2005 a MINUSTAH dirigiu uma missão tática composta por 15 equipes em visitas regionais amplas, para avaliar as condições logísticas e de segurança para celebração das eleições ${ }^{14}$.

\footnotetext{
11 UN. Doc. S/2004/698, 2004, p. 07, \28.

12 UN. Doc. S/2004/908, 2004, p. 06, \ 28.

${ }^{13}$ Entre essas decisões ficou estabelecido que, no dia 5 de outubro de 2004 ficou decidido que as eleições locais seriam realizadas em 06 de novembro de 2005 e as eleições presidenciais no dia 27 de novembro de 2005, e com opção de um possível segundo turno para o dia 18 de dezembro de 2005. O CEP estabeleceu junto com a MINUSTAH que seria necessário 43.9 milhões de dólares para a organização das eleições, o governo de transição entrando com 2,9 milhões de dólares, no entanto esperava que a comunidade internacional entrasse com 41 milhões de dólares (UN. Doc. S/2004/908, 2004, p. 29, \29).

14 UN. Doc. S/2005/124, 2005, p. 08, \ 32.
} 
Uma grande preocupação para a MINUSTAH no período de transição se referiu a algumas disposições presentes na lei eleitoral haitiana, que poderia de acordo com a MINUSTAH, facilitar a reincidência de possíveis contestações aos resultados dos processos eleitorais ${ }^{15}$. No entanto, o governo interino não adotou as recomendações sugeridas pela MINUSTAH para ajustes na lei eleitoral, o que posteriormente refletiu diretamente na execução das atividades de assistência eleitoral, já que, ficou muito difícil evitar que o processo eleitoral ficasse turbinado por uma grande quantidade de candidatos, no qual grande parte da população considerava delinquentes ligados a grupos de natureza delituosa. Essa situação se agravou ainda mais, devido às suspeitas de que as campanhas eleitorais foram financiadas, ao menos em parte, com fundos de procedência duvidosa ${ }^{16}$. Erikson e Minson (2005, p. 3) argumentam que os atores envolvidos na reconstrução do Haiti, ao fato de que a ausência de leis que regulamentasse o financiamento das campanhas dos candidatos e partidos políticos poderiam ofuscar a credibilidade dos processos eleitorais, além do mais, muitos haitianos como interlocutores internacionais acreditavam que o tráfico de drogas poderia emergir como potencial meio de aquisição de recursos para estas campanhas eleitorais.

A análise nos permite perceber que o Secretário Geral fez fortes recomendações às instituições haitianas para que estas tomassem medidas severas frente a estes problemas, pois a descrença da população nos candidatos poderia gerar sérios prejuízos à legitimidade das eleições, além do mais, vale salientar que a participação de varias associações doméstica (partidos políticos) é vista com "bons olhos" num modelo democrático no caso do Haiti, o problema detectado, reside na descrença por parte da população em grande parte desses partidos, o que poderia levar a sérios constrangimentos aos processos eleitorais.

Mesmo estabelecendo um novo corpo burocrático para o CEP em agosto de 2005, a instituição continuou apresentando graves deficiências estruturais e operacionais, o que levou a uma série de dúvidas sobre a capacidade da instituição em cumprir os prazos estabelecidos, uma dessas preocupações residiu na demora da publicação dos locais e das mesas eleitorais e na divulgação de um novo calendário para a celebração das eleições. A própria capacidade da instituição em organizar e gerir as eleições conforme o calendário previsto se colocou como um problema desafiador, e não só isso, os preparativos para as

${ }^{15}$ As disposições da lei eleitoral, fonte de preocupação paraa MINUSTAH foram: a introdução de um direito de apelação diante da Corte de Justiça; a aplicação do princípio de maioria simples para se declarar vencedor no segundo turno das eleições presidenciais e legislativas; e a validade de requisitos especiais para candidatos independentes que não se aplicavam a candidatos partidários (UN. Doc. S/2005/313, 2005, p. 03, \ 09).

${ }^{16}$ UN. Doc. S/2005/631, 2005, p. 04, \} 1 7 . 
eleições seguiram num ritmo mais lento do que o previsto, além de vários problemas de natureza técnica ${ }^{17}$. Ficando assim perceptível a fragilidade do CEP na execução de suas atividades durante o período de transição. A MINUSTAH que estava prestando apoio institucional ao CEP mostrou-se ineficiente em resolver esses problemas, em que muitas vezes, tinham como raízes a má qualificação do pessoal que estava à frente da instituição, bem como os agentes envolvidos no processo.

Durante todo o governo de transição a MINUSTAH contou com o apoio da OEA, do PNUD e do governo interino, estes estiveram conjuntamente inseridos num processo de negociação no tocante ao financiamento para a reestruturação e infraestrutura dos postos eleitorais, além da aquisição de recursos humanos e materiais para o desenvolvimento do processo eleitoral. Porém, esse ponto se demonstrou bastante complicado no período, pois observamos os constantes déficits dos recursos financeiros e morosidade na aquisição desses recursos, o que prejudicou notoriamente o andamento dos processos eleitorais. Por outro lado, houve a imprevisibilidade no que tange o estabelecimento dos orçamentos, isso se deu devido aos problemas de natureza técnica e a emergência das necessidades locais na medida em que avançava o desenvolvimento das atividades de assistência eleitoral, essa imprevisibilidade desencadeou os tais déficits orçamentários que em muitas vezes a comunidade internacional se colocava indisposta a colaborar.

Outro problema detectado nesse período se refere à necessidade da MINUSTAH em ajustar suas atividades diante do contexto haitiano, aplicando regras e padrões tidos como universais, cujo design das atividades se demonstrou incompatível com as particularidades do Estado haitiano, tal incompatibilidade é identificada por Barnett e Finnemore (2004, p. 39), como bureaucratic universalism (universalismo burocrático), uma das patologias das instituições internacionais, em que suas burocracias atuam em vários contextos locais, no entanto, tendem a nivelar as diversidades porque elas são concebidas supostamente como geradoras universais de normas e categorias que se tornam por design desatentas as particularidades do contexto. No que tange a atuação da MINUSTAH, parte dessa visão aponta para o comportamento da operação ao considerar o seu conhecimento técnico como o modelo propício à execução das atividades, porém quando as circunstancias particulares não são apropriadas ao conhecimento generalizado, isso pode comprometer a eficiência das próprias atividades em campo.

${ }^{17}$ UN. Doc. S/2005/631, 2005, p. 04, $\$ 18$. 
O presidente interino, Boniface Alexandre, mediante decreto presidencial, fixou um novo calendário eleitoral ${ }^{18}$, a MINUSTAH passou a ajudar as autoridades locais a planejar e executar tarefas-chave, como a distribuição de material eleitoral, além de apoiar na organização dos centros eleitorais. Ao mesmo tempo, a missão promoveu um diálogo entre os partidos políticos para a aceitação dos resultados das futuras eleições, assim como um consenso sobre os objetivos políticos básicos que deveriam assegurar a estabilidade política e a governabilidade ${ }^{19}$.

No que se refere aos mandatos do CSNU expedidos para o período de transição, detectamos uma nítida deficiência destes no que se refere à especificidade de norteamento para a MINUSTAH, os mandatos apresentavam-se muito dispersos e não direcionavam nem estabeleciam estratégias focais diante dos obstáculos enfrentados pela missão, o que acabava levando a um processo de ineficiência na execução das atividades de assistência eleitoral. A incidência desses problemas reflete o próprio despreparo da MINUSTAH em desenvolver novas estratégias para contemplar as necessidades advindas do contexto local, isso nos remete a outra "patologia" identificada por Barnett e Finnemore (2004), the irrationality of rationalization (a irracionalidade da racionalização) ${ }^{20}$, ou seja, a operação ficou tão presa às normas institucionais pré-estabelecidas e por isso não conseguia se adaptar as ocorrências advindas da realidade haitiana.

\subsection{Governo René Préval (2006-2011)}

O acontecimento político mais importante realizado em 2006, precisamente em 07 de fevereiro, concerne à celebração de eleições parlamentares e presidenciais, registrando uma participação de mais de $60 \%$ dos votantes inscritos ${ }^{21}$. No dia 14 de fevereiro de 2006 , o CEP totalizou a contagem dos votos, e com 51,21\% dos votos válidos declarou René Préval presidente do $\mathrm{Haiti}^{22}$. Na realização dessas eleições alguns problemas foram detectados,

\footnotetext{
${ }^{18}$ Segundo o novo calendário eleitoral fixado, “[...] o primeiro turno das eleições nacionais se celebraria em 07 de fevereiro de 2006 e o segundo turno em 19 de março e o novo presidente tomaria posse em 29 de março de 2006; e celebraria as eleições municipais e locais em 30 de abril de 2006" (UN. Doc. S/2005/060, 2006, p. 01). ${ }^{19}$ UN. Doc. S/2005/060, 2006, p. 02, \05.

20 "Max Weber reconheceu que o processo de racionalização que as burocracias exerciam poderia ser levado ao extremo e finalmente tornar-se irracional se as regras e procedimentos que as burocracias utilizavam para executar os seus trabalhos tornavam-se fins em si mesmo, ao invés de projetar as regras mais adequadas com procedimentos eficientes no cumprimento de suas missões, as burocracias muitas vezes atuam sob medidas dentro dos meios já existentes, bem conhecidos, confortáveis; assim, esses meios (normas e procedimentos) passam a ser tão incorporados e poderosos que eles determinam os fins e a maneira de como a organização define os seus próprios objetivos [tradução livre]" (BARNETT e FINNEMORE, 2004, p. 39).

${ }^{21}$ UN. Doc. S/2006/592, 2006, p. 01, \03.

22 UN. Doc. S/2006/592, 2006, p. 02, \ 06.
} 
como a fragilidade na segurança dos postos eleitorais e problemas de natureza técnica foram perceptíveis, esses foram acontecimentos pontuais que não comprometeram a legitimidade do pleito, mas o que mais foi preocupante para a MINUSTAH, residiu no desempenho dos agentes eleitorais, que na maioria das vezes não conseguiam desenvolver soluções práticas e eficientes diante dos desafios das necessidades particulares, isso se deve muito à má qualificação profissional desses agentes, fato que passou a ser fonte de denúncias de fraudes nos processos eleitorais.

Aliada a má qualificação dos agentes eleitorais, havia dificuldades de integração entre as atividades de assistência eleitoral executada pela MINUSTAH, grande parte desses obstáculos no desenvolvimento de um processo de integração que resultasse na execução de atividades eficientes, esteve ligado às diferentes percepções dos agentes eleitorais em executar tais atividades, culturas distintas o que acabava dificultando o processo de integração (entre os diversos as atividades de assistência eleitoral), isso reflete ao que Barnett e Finnemore (2004), identificam como cultural contestation (contestação cultural), uma das "patologias" presente nas burocracias das instituições internacionais.

Diante dessas dificuldades, a discussão que permeava a MINUSTAH seria rediscutir o seu papel no período pós-eleitoral, sendo assim, o CSNU realizou uma ampla avaliação do mandato da MINUSTAH que do ponto de vista prático, resultou em amplos intercâmbios entre a missão e a sede da ONU, para estabelecer qual seria o papel apropriado à operação no período pós-eleições.

O processo de avaliação do mandato da MINUSTAH pelo CSNU foi fundamental dado a necessidade de redimensionar o papel daquela operação no que se refere à execução de suas atividades no campo eleitoral, estabelecendo uma clara divisão do trabalho entre os principais agentes pertinentes além do mais, o Haiti ainda apresentava problemas políticos e estruturais, na medida em que o novo governo eleito ainda era politicamente frágil, no entanto, a missão não poderia perder o seu foco central resguardado no apoio ao processo constitucional e político do Estado haitiano. Algumas recomendações também foram feitas pelo Secretário Geral, entre elas, delegou funções ao representante especial do ONU no Haiti, recomendando que este atuasse no fortalecimento das instituições domésticas e gerando um ambiente de diálogo e negociação para facilitar as resoluções das possíveis controvérsias políticas, e para isso seria fundamental que o povo haitiano participasse de todo esse processo.

O novo presidente e os novos parlamentares eleitos para a administração pública nas eleições celebradas herdaram instituições totalmente débeis, que adoeceram diante da 
escassez de profissional qualificado, de uma infraestrutura deficiente, de recursos e materiais limitados. Em resposta a estas dificuldades, a MINUSTAH seguiu melhorando os aparatos técnicos, promovendo a coordenação entre as atividades de assistência internacional e as instituições locais, promovendo assessoramento especializado na criação de instituiçõeschave, como o Escritório do Presidente, os principais ministérios, o parlamento e os órgãos locais pertinentes ${ }^{23}$. Aqui temos que ter em mente, que uma das últimas fases do ciclo eleitoral ligado às atividades de assistência eleitoral, concerne à promoção do fortalecimento das instituições administrativas do Estado.

Dando prosseguimento ao processo eleitoral, nas eleições municipais e locais realizadas em 03 de dezembro de 2006, a MINUSTAH prestou assistência logística e de segurança nas eleições, entre outras tarefas, executou a distribuição das listas de votantes a 140 centros eleitorais nos municípios, de pastas contendo material para capacitar os agentes eleitorais ${ }^{24}$. Ainda que a situação da segurança fosse naquele momento considerada um constrangimento para uma maior presença de eleitores nos centros de votação, o nível de participação de 30\%, segundo o pessoal da MINUSTAH foi maior que o esperado pelos partidos políticos. Mesmo assim, ainda considerava possíveis apelações nos dias posteriores a realização das eleições, dado que devido a pontuais movimentos de insurgência, foram destruídos alguns centros de votação, e em consequência, alguns dados informativos que estavam criptografados foram perdidos ${ }^{25}$.

Analisando os informes concernentes aos anos de 2007 e 2008, conseguimos detectar a forte contribuição da MINUSTAH para o planejamento dos aspectos logísticos e para a segurança das eleições dos senadores; a MINUSTAH também exerceu um papel fundamental na organização e mediação de vários fóruns e debates entre os partidos políticos e a sociedade civil, no tocante as questões de governança e corrupção, foram dois temas presentes e fundamentais nas discussões já que como visto no histórico haitiano, a má governança foi historicamente característico das elites locais haitianas, e nos tempos mais recentes as denuncias de corrupção contra os dirigentes públicos passaram a ser recorrentes na política haitiana.

A MINUSTAH em parceria com o CEP iniciou um processo de contratação de agentes eleitorais para as eleições do Senado, para suprir seus 11 escritórios regionais, 142 escritórios locais em conformidade com as necessidades colocadas pela lei eleitoral. Todo o

${ }^{23}$ UN. Doc. S/2007/503, 2007, p. 04, \$12.

${ }^{24}$ UN. Doc. S/2006/1003, 2006, p. 01, \$ 03.

${ }^{25}$ UN. Doc. S/2006/1003, 2006, p. 02, \$04. 
pessoal a nível regional ocupou seus postos em fevereiro de 2009 e o pessoal a nível local previa para o início de março de $2009^{26}$. A avaliação dos recursos humanos prestado pela MINUSTAH foi peça fundamental para a execução dos processos eleitorais, porém o recrutamento de agentes eleitorais qualificados tinha sido um grande desafio enfrentado pela operação em campo.

As eleições para o Senado realizadas em 19 de abril de 2009 registraram poucos casos de violência durante o processo eleitoral, mas o que deixou a MINUSTAH e a comunidade internacional mais preocupada foram a baixa participação da população no processo político eleitoral, não ultrapassando a casa dos $11,3 \%{ }^{27}$. As atividades de assistência eleitoral foram seriamente comprometidas nesse período devido à introdução de uma nova lei eleitoral redigida pelo CEP e aprovada pela legislatura ${ }^{28}$, entre algumas disposições da nova lei eleitoral estava o aumento no número de postos de votação, no entanto, diante da complexidade organizacional desses novos centros de votação a MINUSTAH se demonstrou ineficiente, além do mais a operação não conseguiu estabelecer um coordenamento eficiente capaz de integrar ao seu comando e ao seu controle os novos centros de votação.

Entre os anos de 2008 e 2009, há em certa medida, omissão por parte do CSNU para com os acontecimentos desencadeados no Haiti durante esse período, já que durante os anos supracitados, o órgão só se manifestou apenas uma única vez por ano, além do mais, os mandatos expedidos referentes ao setor eleitoral, na medida em que foram muito abrangentes, tornaram-se vagos, pois não havia um direcionamento focal para a atuação da operação no campo da assistência eleitoral, esse fato levou a uma incompatibilidade entre as resoluções do CSNU e as necessidades em termos de recursos para a execução das atividades da MINUSTAH, delegando à operação mandatos para além das suas capacidades estruturais. Além do mais, os mandatos continuaram vagos e pouco se adequavam a realidade haitiana, gerando constatimente a necessidade do Secretário Geral colocar em alto relevo a situação do Haiti, introduzindo-o sempre que possível na agenda do Conselho de Segurança, como a

\footnotetext{
${ }^{26}$ UN. Doc. S/2009/129, 2009, p. 04, \14.

27 UN. Doc. S/2009/439, 2009, p. 04, \ 12.

28 A nova lei eleitoral que foi redigida pelo CEP e apresentada ao governo e ao parlamento em fevereiro de 2008, foi aprovada na legislatura em 9 de julho de 2008 e publicada em 25 de julho do mesmo. Na nova lei eleitoral se introduziu varias mudanças, entre elas, o aumento no numero dos centros de votação, o aumento no número de deputados (de 99 para 142), a disposição de que se incluam os votos em branco nos resultados das eleições, além de medidas para melhorar a transparência do processo eleitoral. O CEP se empenhou para examinar as estruturas e recursos tanto a nível central e local para colocar em prática os requisitos da nova lei eleitoral. Dos 821 centros existentes, foi delegada a construção de mais 540 novos centros, a MINUSTAH dentro de suas capacidades e limitações, esteve inserida na colaboração com o CEP, prestando assistência logística, técnica e de segurança para facilitar as atividades do desenvolvimento das atividades da instituição ligada ao setor eleitoral (UN. Doc. S/2008/586, 2008, p. 03, § 9 e 10).
} 
necessidade da própria operação executar atividades compatíveis com as demandas locais, não se prendendo as regras pré-estabelecidas (recuperemos aqui a irrationality of rationalization), para que não provoque o esvaziamento dos objetivos da operação.

No dia 12 de janeiro de 2010 um terremoto de magnitude 7,0 aterrorizou o Haiti, principalmente as cidades de Petit Goâve, Léogâne, Jacmel, Miragoâne e a capital Porto Príncipe. Segundo o governo do Haiti, cerca de 222.570 pessoas morreram, milhares ficaram incapacitadas permanentemente e 1,5 milhões de pessoas perderam suas moradias ${ }^{29}$. A capacidade do Estado haitiano foi gravemente afetada. Dois senadores morreram e muitos altos dirigentes políticos ficaram feridos, as eleições que estavam previstas para fevereiro de 2010, se postergaram gerando assim, um clima de incertezas políticas.

O Terremoto interrompeu um período de relativo andamento dos processos eleitorais. Em 27 de Janeiro de 2010, o presidente Préval anunciou o retardamento das eleições legislativas que estavam previstas para Fevereiro de 2010, o que provocou inquietude devido à fragilidade política e eleitoral que o Haiti estava tentando solucionar, além do mais, o vencimento dos mandatos e de um terço dos Senadores estavam próximos de ocorrer, ainda apontando a organização das eleições presidenciais, pois segundo a Constituição haitiana, deveria haver eleições a tempo para a transferência do mandato como se exige, como deve expirar o mandato do presidente Préval em 7 de Fevereiro de 2011. Diante dessa situação, o presidente haitiano pediu a ONU que avaliasse as condições necessárias para a celebração destas eleições e estudar a melhor opção para fixar um calendário eleitoral. Em resposta a este pedido o Secretário Geral, enviou ao Haiti uma comissão composta por agentes do Departamento de Assuntos Políticos, PNUD e o Departamento de Operações de Paz, para uma avaliação mais ampla sobre as diretrizes a serem executadas ${ }^{30}$.

A ênfase nas atividades de assistência eleitoral se dá quando uma missão multidisciplinar enviada pelo Secretário Geral ao Haiti, concluiu que seria tecnicamente viável celebrar as eleições presidenciais, parlamentares antes do final de 2010. No entanto, em 24 de Junho de 2010, o governo decretou ao CEP o mandato de organizar as eleições presidenciais, fixando para o dia 28 de Novembro de 2010 a data de realização das eleições presidenciais e legislativas, a MINUSTAH começou a coordenar a assistência eleitoral internacional em colaboração com alguns organismos, em particular com a OEA e a CARICOM $^{31}$, outro papel delegado a MINUSTAH foi à inspeção dos 1.483 colégios

${ }^{29}$ UN. Doc. S/2010/200, 2010, p. 01, \02.

${ }^{30}$ UN. Doc. S/2010/200, 2010, p. 19, \$ 06.

${ }^{31}$ UN. Doc. S/2010/446, 2010, p. 04, § 13. 
eleitorais do país, e a localização de novos lugares para substituir os centros eleitorais que haviam sofrido danos estruturais provocados pelo terremoto. A MINUSTAH também começou a preparar um plano integral de segurança e logística eleitoral que compreende desde a prestação de serviços de escolta aos observadores eleitorais, como também a elaboração, fornecimento e proteção do material eleitoral utilizado nos centros eleitorais ${ }^{32}$. $\mathrm{Na}$ execução dessas atividades do período pré-eleitoral, a MINUSTAH esteve mais interligada com outras organizações internacionais, a exemplo da CARICOM e OEA, porém um fator determinante na execução de suas atividades foi o déficit financeiro que passou a retardar o andamento do processo preparatório.

Durante o governo de Préval, o CSNU delegou mandatos à MINUSTAH para a inclusão das mulheres nos processos políticos haitianos, no entanto, o que ficou evidente na avaliação dos informes referentes a esse período foi uma quase inexistência da atuação prática da MINUSTAH na execução desses mandatos, em raros momentos a operação esteve incluída na promoção e no apoio das questões de gênero, nem no incentivo dos partidos políticos para a participação das mulheres nos processos políticos haitianos.

Durante parte do governo Préval, a MINUSTAH apresentou grandes dificuldades na execução do planejamento e no coordenamento entre seus subsetores, dificuldades advindas principalmente das diferentes visões entre estas subunidades, aqui resgatemos a cultural contestation (contestação cultural) identificada por Barnett e Finnemore (2004, p. 40), pois haviam diferentes políticas praticadas nas diferentes subunidades, estas compostas por indivíduos de diferentes culturas internacionais que têm distintas formas de perceber o ambiente, elaboram diferentes tarefas e objetivos, resultando em um choque de perspectivas que geram tendências patológicas.

No dia 28 de novembro de 2010, o Haiti celebrou o primeiro turno das eleições presidenciais e parlamentares, e foram marcadas por intimidações, denúncias de fraudes e alguns pontos focais de violências ${ }^{33}$. Antes de encerrar a jornada eleitoral, 14 candidatos entraram com um pedido de anulação das eleições alegando a presença de fraudes em alguns colégios eleitorais. No dia 07 de dezembro, as denúncias foram anuladas e o CEP anunciou os resultados preliminares das eleições ${ }^{34}$. Depois de um período de grandes tensões e desafios, no dia 03 de fevereiro de 2011, o CEP anunciou oficialmente, Manigat e Martelly,

32 UN. Doc. S/2010/446, 2010, p. 04, \$15.

${ }^{33}$ UN. Doc. S/2011/183, 2011, p. 01, \$02.

${ }^{34}$ UN. Doc. S/2011/183, 2011, p. 02, \03. 
em primeira e segunda posição respectivamente, e que estavam aptos a concorrer ao segundo turno das eleições presidenciais.

Depois da primeira rodada de eleições, a MINUSTAH esteve em discussões com o CEP, o governo haitiano e a Polícia Nacional Haitiana (PNH), para não repetir os mesmos incidentes na segunda rodada, para isso, passou a desenvolver um plano se segurança para os centros de eleitorais, o CEP se comprometeu em substituir os agentes eleitorais envolvidos em conduta violenta ou fraudulenta. O elemento mais preocupante para a MINUSTAH foi o inesperado retorno do Sul da África do ex-presidente Aristide dois dias antes da realização do segundo turno das eleições, a MINUSTAH bem como as outras instituições envolvidas no processo temia que o retorno de Aristide pudesse reanimar ressentimentos adormecidos e prejudicar o andamento do processo eleitoral. No entanto, a segunda rodada de eleições ocorreu em 20 de março de 2011, em um clima aparentemente geral e tranquilo, ocorreram irregularidades de pouca importância ${ }^{35}$. As discussões e as revisões realizadas pela MINUSTAH observando os pontos críticos notórios no primeiro turno foram essenciais para desenvolver um clima relativamente pacífico na realização do segundo turno das eleições, grande parte disso se deu devido a um reajuste da concepção da PNH na promoção da segurança eleitoral.

\subsection{Governo Michel Martelly (2011-2014)}

Devido a várias pressões de grupos internos, principalmente dos partidos políticos, o CEP começa a receber acusações de corrupção devido o atraso nos resultados das eleições, no entanto, no dia 20 de abril de 2011, a instituição divulgou os resultados definitivos, confirmando a vitória de Michel Martelly (Repons Peyizan), com 67,57\% dos votos, frente ao seu oponente Mirlande Manigat (Rassemblement des démocrates nationaux progressistes), que recebeu 31,74\% dos $\operatorname{votos}^{36}$. Em 14 de Maio de 2011, Michel Joseph Martelly prestou juramento como sucessor de René Préval, assumindo assim, o cargo de Presidente do Haiti. Nos primeiros meses de seu governo, Martelly tem enfrentado um grande entrave com o parlamento, no que refere à nomeação de um novo Primeiro Ministro. O impasse político entre o parlamento e o presidente tem sido fator preocupante para a MINUSTAH, pois há o eminente risco de soterrar os avanços dos processos políticos já conquistados e desencadear no agravamento da segurança local ${ }^{37}$. Diante dessa atmosfera, a MINUSTAH

35 UN. Doc. S/2011/183, 2011, p. 03, \08.

36 UN. Doc. S/2011/540, 2011, p. 02, \$03.

${ }^{37}$ UN. Doc. S/2011/540, 2011, p. 02, \$ 01. 
esteve inserida na mediação de um processo de diálogo, que tentasse minimizar os entraves entre o presidente e o parlamento.

Durante o período a ONU prestou assistência crucial ao processo eleitoral realizado, a missão recuperou e entregou o material eleitoral confidencial e não confidencial, prestou serviços de segurança aos colégios eleitorais, principalmente aqueles que apresentavam o maior número de ocorrências. No período pós-eleições, a MINUSTAH realizou 52 missões de avaliações e controle da situação aonde se registraram os principais incidentes violentos durante as eleições, prestando apoio a autoridades judiciais, além de realizar 37 processos de mediação política entre os partidos dos candidatos legislativos opositores, além de trabalhar na facilitação da reabertura das prefeituras e tribunais locais nas zonas afetadas pela violência provocada pelos ânimos alterados durante a realização da celebração das eleições presidenciais $^{38}$. Durante o ano de 2013 a MINUSTAH se concentrou no apoio político e fortalecimento do CEP. Em 2014, a operação se concentrou no apoio institucional ao CEP no para a preparação das eleições parlamentares e municipais. Desta forma, o campo da assistência eleitoral se estende por todo um ciclo político, institucional e eleitoral, o momento pós-eleições é fundamental para que as autoridades possam estabelecer a governança nos seus níveis delegados, contribuindo assim para a sustentação e efetivação das estruturas de poder local.

Percebe-se, portanto, que o auxilio da ONU no campo da assistência eleitoral no Haiti, até o momento analisado, entre obstáculos, avanços e retrocessos, já conseguiu realizar duas transições de governos, transições eleitorais tidas como democráticas, embora houvesse certos índices de violência e desordem em alguns pontos focais, algumas denúncias de fraudes. No entanto, o atraso das recentes eleições parlamentares e municipais coloca em observância o andamento da democracia haitiana. Por outro lado, mesmo em meio a algumas insuficiências burocráticas, a ONU tem influenciado diretamente nas atividades dos processos eleitorais e abertura de diálogos políticos no Haiti.

\section{CONSIDERAÇÕES FINAIS}

A experiência da ONU no campo da assistência eleitoral no Haiti nos revela que a instituição se envolveu em todas as fases do processo eleitoral e em grande parte do processo de democratização do Estado haitiano, embora muito ainda tenham a se fazer, alguns avanços devem ser considerados. A operação obteve grande êxito nos processos de negociação para a implementação das eleições, isso de deu devido a grande prática do diálogo

${ }^{38}$ UN. Doc. S/2011/540, 2011, p. 05, 』16. 
promovido pela missão para chegar a um consenso entre os grupos políticos locais, a celebração de eleições, mesmo que em meio a alguns desafios os processos eleitorais foram realizados e o fornecimento do apoio técnico e logístico necessário para a realização dos processos eleitorais.

Por outro lado, a MINUSTAH enfrentou grandes obstáculos e desafios que muitas vezes comprometeram o êxito de forma mais rápida da operação, grande parte desses obstáculos esteve ligado aos déficits financeiros (morosidade na aquisição dos recursos) decorrente da imprevisibilidade do planejamento orçamentário, além da relativa ausência de doação por parte dos Estados, problemas ligados a mau planejamento eleitoral, má qualificação dos agentes eleitorais, que comprometiam seriamente a execução das atividades, além da ausência de expertise no desenvolvimento das tarefaras delegadas, não sabiam lidar diante dos problemas advindos das demandas locais, mandatos inadequados (irracionalidade da racionalização), ficando evidente a incongruência entre as resoluções do Conselho de Segurança e as necessidades reais da operação em campo, além das necessidades de integração entre as unidades, dificultada pelas diferentes percepções de como executar as atividades (contestação cultural).

Nesse sentido, o CSNU deve estabelecer mandatos apropriados, compatíveis com as necessidades das atividades da ONU no campo da assistência eleitoral no Haiti, e para que esta possa assim, reduzir ou minimizar os efeitos de sua insuficiência burocrática e delinear melhor execução das atividades condizentes com a realidade haitiana e se adequando constantemente as necessidades advindas do contexto local. De fato, as perspectivas futuras para o Haiti dependem em grande parte do compromisso político das próprias elites haitianas, bem como do engajamento e da participação do povo haitiano no prosseguimento e efetivação da política doméstica, que atentos ao cumprimento dos processos eleitorais, protestam a fim de promover a periodicidade das eleições e a estabilização de um Estado democrático no Haiti.

\section{REFERÊNCIAS}

BARNETT, M.; FINNEMORE, M. (2004). Rules for the world: International Organizations in Global Politics. USA. Cornell University Press.

BUSS, T. F. (2008). Haiti in balance: Why foreign aid has failed and what we can do about it. Terry Buss with Adam Gardener. Washington: Brookings.

CÂMARA, I. P. de L. (1998). Em nome da democracia: OEA e a crise Haitiana (1991-1994). Brasília: IRB/FUNAG/CEE. 
CAVALLARO, J. (2005). Mantendo a paz no Haiti? Uma avaliação da missão de estabilização das Nações Unidas no Haiti usando o cumprimento de seu mandato como parâmetro de sucesso. Rio de Janeiro: Centro de Justiça Global.

DECLARAÇÃO UNIVERSAL DE DIREITOS HUMANOS. (1968). Disponível em: [http://www.un.org/Overview/rights.html], [25/11/2014].

DOYLE, M. (19983). Kant, liberal legacies, and foreign affairs. Philosophy and public affairs, Vol. 12 , No 3, p. 205-235.

2010.

. (2010). Liberal internationalism: peace, war and democracy. Nobelprice.org. 12, August,

ELECTORAL ASSISTANCE IMPLEMENTATION GUIDE. (2007). Elaborado pelo UNDP. Disponível em: [http://www.undp.org/governance/docs/UNDP-ElectoralAssistance-Implementation-Guide.pdf] [15/10/2014].

ERIKSON, D. P.; MINSON, A. (2005). Haiti preparing for election. Conference Report. Washington: Inter-American Dialogue.

FATTON, R. Jr. (2006). The fall of Aristide and Haiti's current predicament. Canada: Wilfrid Laurier University Press, p. 15-24.

GALTUNG, J. (1969). Violence, Peace, and Peace research, Journal of peace research, Vol. 6, No. 3, 1969, p. 167-191.

HAGMAN, L. (2002). Lessons Learned Peacebuilding in Haiti. IPA Seminar Report. New York: International Peace Academy.

HANDBOOK ON UN MULTIDIMENSIONAL PEACEKEEPING OPERATION. (2003). Disponível em: [http://www.peacekeepingbestpractices.unlb.org/Pbps/library/Handbook\%20on \%20UN \%20PKOs.pdf] [15/10/2014].

INTERNATIONAL CRISIS GROUP. (2004). A new chance for Haiti? ICG Latin America Caribbean. Report No10. Disponível em: [http://www.crisisgroup.org/ /media/Files/latin-america/haiti/10-a-new-chance-forhaiti] [28/03/2015].

JEONG, Ho-Won. (2010). Conflict management and resolution: An Introduction. London: Routledge, p. 192-213.

KANT, I. A pazperpétua e outros opúsculos. Lisboa: Edições 70, 2008.

KRATOCHWIL, F.; RUGGIE, J. G. (1986). International organization: a state of the art on an art of state. In: International Organization, vol. 40, n. 044, p. 336-363.

MELO, R. B. C. L. (2006) Construindo as operações de paz multidimensionais das Nações Unidas. Tensões Mundiais, Fortaleza, Vol. 2, No 01, p. 408-433. 
(2006). Oprocesso de institucionalização das operações de paz multidimensionais da ONU no pós-guerra fria: direitos humanos, polícia civil e assistência eleitoral. Tese de Doutorado. Pontifícia Universidade Católica do Rio de Janeiro. Instituto de Relações Internacionais. Programa de Pós-Graduação em Relações Internacionais. Rio de Janeiro,

OWEN, J. M. (1999). How liberalism produces democratic peace. In: Theories of ear and peace: an international security reader. Organized by BROWN, Michael E.; OWEN, R. Coté; LYNNJONES. JR., Sean M.; MILLER, Steven E. Cambridge: MIT Press.

PACTO DOS DIREITOS CIVIS E POLÍTICOS. (1966). Disponível em: [http://www.dhnet.org.br/direitos/sip/onu/doc/pacto2.htm] [25/10/2014].

RELATÓRIO BRAHIMI. (2000). Disponível em: [http://www.unric.org/html/portuguese/peace/pkpngfaq/q3.htm] [20/10/2014].

UNITED NATIONS. Resolutions of the Security Council. (2004-2014). United Nations Documents Disponivel em: [http://www.un.org/en/peacekeeping/missions/minustah/resolutions.shtml] [20/10/2014].

- Reports of the Secretary-General. (2004-2014). United Nations Documents. Disponivel em: [http://wnw.un.org/en/peacekeeping/missions/minustah/reports.shtml] [22/10/2014]. 